\title{
Prostate Ductal Adenocarcinoma, Solid Pattern
}

National Cancer Institute

\section{Source}

National Cancer Institute. Prostate Ductal Adenocarcinoma, Solid Pattern. NCI

Thesaurus. Code C39897.

A prostate ductal adenocarcinoma characterized by the presence of cribriform and/or papillary patterns and areas of solid nests of malignant cells. 